\title{
Changes in Microbial Quality of Irrigation Water Under Different Weather Conditions in Southeast Norway
}

\author{
Adam M. Paruch • Trond Mæhlum • Lucy Robertson
}

Received: 1 December 2014 / Accepted: 7 December 2014 /Published online: 19 December 2014

(C) Springer International Publishing Switzerland 2014

\begin{abstract}
A short-term study concerning the impact of weather fluctuations in Southeast Norway on microbiological quality of irrigation water sources was performed. The weather variations were related to a relatively dry and warm period followed by rainfall events associated with lower air temperatures. Samples of water from a ground well, a pond and a stream, all used for sprinkler irrigation of fruit and vegetable crops, were investigated for contamination with faecal indicator bacteria (Escherichia coli - E. coli) and intestinal parasitic protozoa (Cryptosporidium oocysts and Giardia cysts). Although the groundwater was not contaminated with these microbes during either period, contamination was detected in surface waters, with concentrations up to three times higher during the wet/cool period than during the dry/warm period. An increase in microbial concentrations was observed immediately after the first rainfall events. These results demonstrate that surface waters commonly used for irrigation in Southeast Norway are vulnerable to contamination with microbes and this is related to weather fluctuations. These outcomes are of relevance when considering the impact of predicted climate change and contamination of agricultural water supplies.
\end{abstract}

Keywords Climate Cryptosporidium $\cdot$ Escherichia coli $\cdot$ Giardia $\cdot$ Irrigation water

\section{Introduction}

Water overexploitation across Europe poses a threat to water resources, and problems with water scarcity have been widely reported. Although these problems have been most acute in southern Europe, the spatial extent and severity of water stress also affects the northern parts (European Environment Agency 2009). The European Commission (2007) estimated that at least $11 \%$ of Europe's population and $17 \%$ of its territory have already been affected by water scarcity. These problems are likely to be more severe in the future, with predicted increases in the frequency and severity of droughts. In addition, frequent episodes of extreme precipitation

\footnotetext{
A. M. Paruch $(\bowtie) \cdot$ T. Mæhlum

Bioforsk - Norwegian Institute for Agricultural and Environmental Research, Frederik A. Dahls vei 20, N-1430 Aas, Norway

e-mail: adam.paruch@bioforsk.no

L. Robertson

NMBU - Norwegian University of Life Sciences, Adamstuen Campus, P.O. Box 8146, Oslo, Norway
} 
have been reported. Such events, in particular short but intense rainfall, provides only a minimal contribution to recharging of aquifers, as runoffs predominates over infiltration of rainwater, and this may impact on the natural balance of ecosystems, human and environmental health, and agricultural productivity.

In Norway, over $90 \%$ of water consumed is obtained from surface water, and this is highly affected by warmer climatic conditions, with shorter periods of ice cover and longer periods with water circulation, resulting in a reduction in the efficacy of some hygienic barriers against pathogenic microorganisms (Tryland et al. 2011). Furthermore, extreme precipitation and runoff will cause an increased risk of microbial pathogen contamination of water sources. This may develop into a spiral of more infections, greater contamination, and thus further increases in the risk of infection with waterborne diseases (Tryland et al. 2011).

These consequences are likely to affect agronomic productivity, especially in locations where agricultural practices depend upon irrigation water. This is of both local and global importance as $18 \%$ of cropland globally, producing $40 \%$ of all food, is dependent on irrigation (Carr et al. 2004).

Most pathogenic microorganisms responsible for waterborne diseases originate from a faecal-oral transmission route. Therefore, faecal indicator bacteria (FIB) are frequently investigated in determining the hygienic quality of water. In addition, there are a range of human intestinal pathogens, including some with zoonotic potential, that threaten the sanitary conditions of water; these include a range of bacteria, viruses and parasitic protozoa.

Within the FIB group, E. coli bacteria are the most commonly used as indicators of faecal contamination in the natural environment of water, soils and plants (Edberg et al. 2000; Lee et al. 2006; Haller et al. 2009; Palese et al. 2009). E. coli commonly colonises the lower gastrointestinal tract of warm-blooded animals (mammals, including humans, and birds) and from there, its preliminary transmission to the environment occurs via faeces, where individual E. coli can be found at concentrations of $1 \times 10^{9}$ per gram of faecal matter (Edberg et al. 2000). The occurrence of $E$. coli bacteria in the environment is thus a suitable indicator of contamination with faecal matter (Paruch and Mæhlum 2012).

Cryptosporidium and Giardia are recognised as important pathogenic parasites that can be transmitted by the waterborne route. Cryptosporidium oocysts and Giardia cysts are fairly robust and resistant in the environment, and thus are widely present in water around the world, causing waterborne outbreaks of infection (Karanis et al. 2007; Baldursson and Karanis 2011). Although in Norway the potential for waterborne transmission of the protozoan parasites, Cryptosporidium and Giardia, has been considered of minor significance, contamination of water and food by protozoan cysts and oocysts had also been reported (Robertson and Gjerde 2001a, b). Moreover, an extensive outbreak of waterborne giardiasis occurred during 2004/ 2005 in Bergen, the second largest city in Norway (Robertson et al. 2006), and this has resulted in an increased focus on the contamination of Norwegian water sources with these parasites (Gaut et al. 2008; Robertson et al. 2009; Tryland et al. 2011). Furthermore, there have been various outbreaks of waterborne and foodborne cryptosporidiosis in other countries in Scandinavia, particularly Sweden (Robertson and Chalmers 2013).

Climate change with more frequent alternating episodes of long-lasting warm and dry periods, and short-lasting but extreme events of precipitation will directly affect the microbial quality of water bodies. Therefore, in order to protect human and environmental health, the faecal contamination of water sources, especially those used for drinking water and for the irrigation of fruits and vegetables commonly consumed as fresh produce, should be regularly monitored (Tryland et al. 2011). For agricultural practices, this is particularly important during the relatively dry and short growing season, when the higher water demands for irrigation last until sufficient precipitation occurs. Currently there is little information on the effects of local 
weather conditions on the microbial quality of irrigation water in Norway. The purpose of this short communication is therefore to briefly present results of a preliminary study investigating the effects of weather variability on changes in concentrations of intestinal bacteria and protozoa in waters used for seasonal irrigation in Southeast Norway.

\section{Materials and Methods}

\subsection{Study Sites and Testing Materials}

The study was conducted on water samples collected in the agricultural areas of two municipalities, Ås and Råde, located approximately 30 and $60 \mathrm{~km}$ south of Oslo City, respectively (Fig. 1). Three types of waters were examined: groundwater, standing surface water and flowing surface water, acquired from a groundwater well (3.5 $\mathrm{m}$ in depth), a pond and a stream, respectively. These waters serve as raw water-supply sources for sprinkler irrigation, which is the most common irrigation method in Southeast Norway.

Water samples from the ground well and the pond were collected on a strawberry plantation in the municipality of Ås (Fig. 1). These two water sources have been selected because they were commonly used in past years for the irrigation of strawberries, which were sold seasonally on the local market.

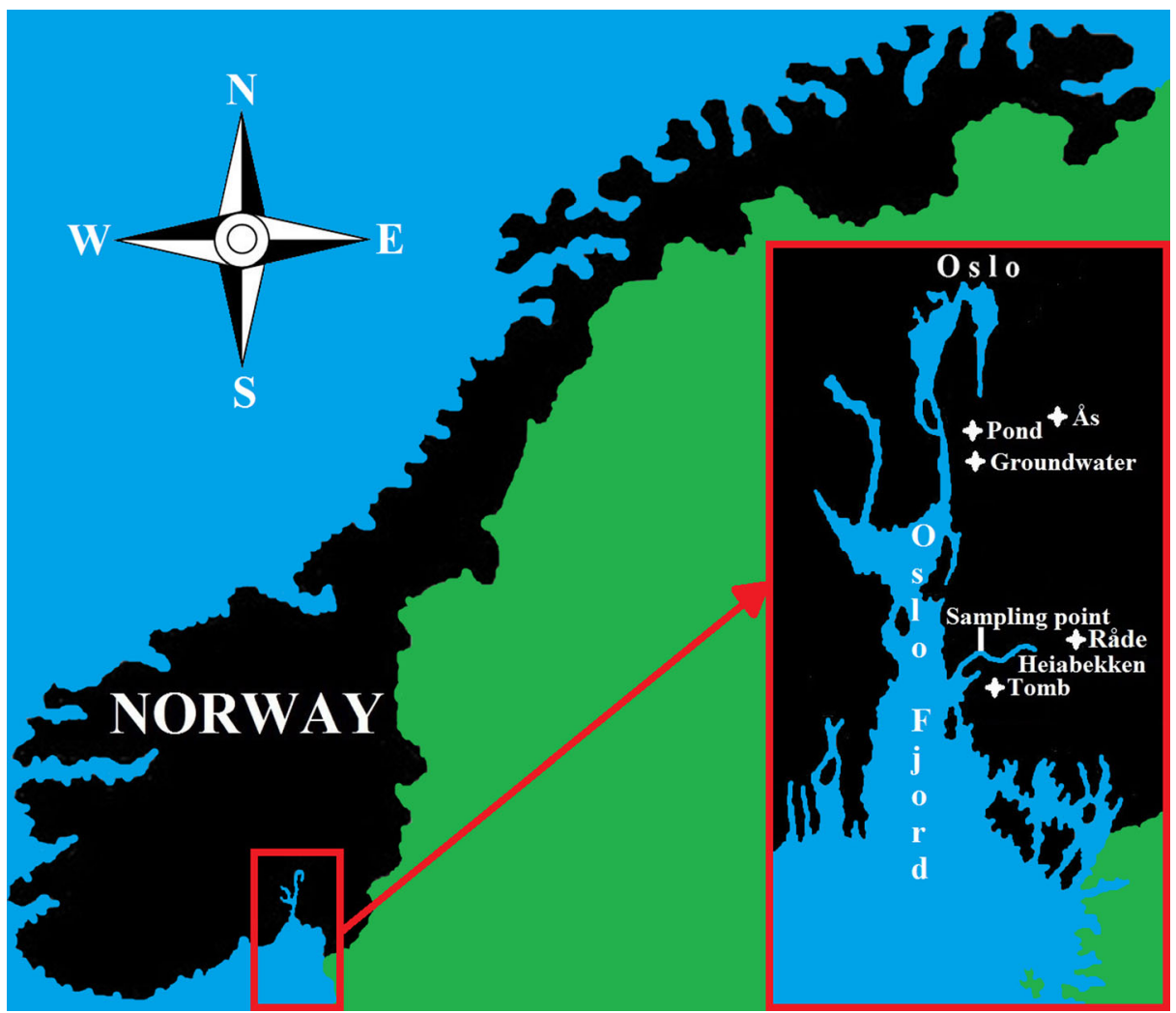

Fig. 1 Location of the study sites in Southeast Norway 
Stream water samples were acquired in the rural district of the municipality of Råde, from a stream named Heiabekken, which reaches the Oslo Fjord via the Kure Fjord (Fig. 1). This stream was selected because a poultry farm, which included a breeding farm of 250000 chickens and a layer farm of 5000 hens, was located in the area upstream of Heiabekken (approximately $2 \mathrm{~km}$ above the sampling point). Therefore, a potential impact of the farms on stream water quality had been predicted. Water from this stream has been regularly used for the irrigation of various vegetable crops, including potatoes, maize, carrots, parsley, beetroot, cabbages, onions and leeks. Due to the agricultural characteristics and scattered locations of the sampling sites, and the fact that direct pollution from human point sources was not identified during inspection of the sampling sites, the effect of human faecal pollution on the microbial quality of tested water was considered to be minimal.

Sampling was conducted on nine occasions (nine sampling sets, each including three different samples of water collected from the ground well, the pond and the stream) in the course of a 1-month period, starting at the end of May 2008. This period was chosen to coincide with the growing season and the main agricultural activities in Southeast Norway, which begin at around April - May; irrigation requirements are usually considerable from May to July. The sampling period was therefore set in the middle of irrigation season. Interestingly, May 2008 was very dry in comparison with previous May months of the current century, as based on climatic data from the AgroMetBase hosted by Bioforsk - Norwegian Institute for Agricultural and Environmental Research and obtained from two weather stations situated close to the study sites. One weather station located in Ås was used for weather conditions at the ground well and pond sampling sites. The other station, located in Tomb, recorded weather conditions in the vicinity of the Heiabekken sampling site (Fig. 1). The sampling schedule in comparison with the weather data are summarised in Fig. 2.

\subsection{Identification of Microbial Water Pollution}

Faecal indicator bacteria represented by $E$. coli, and intestinal parasitic protozoa represented by Cryptosporidium and Giardia were selected as relevant markers of contamination of irrigation

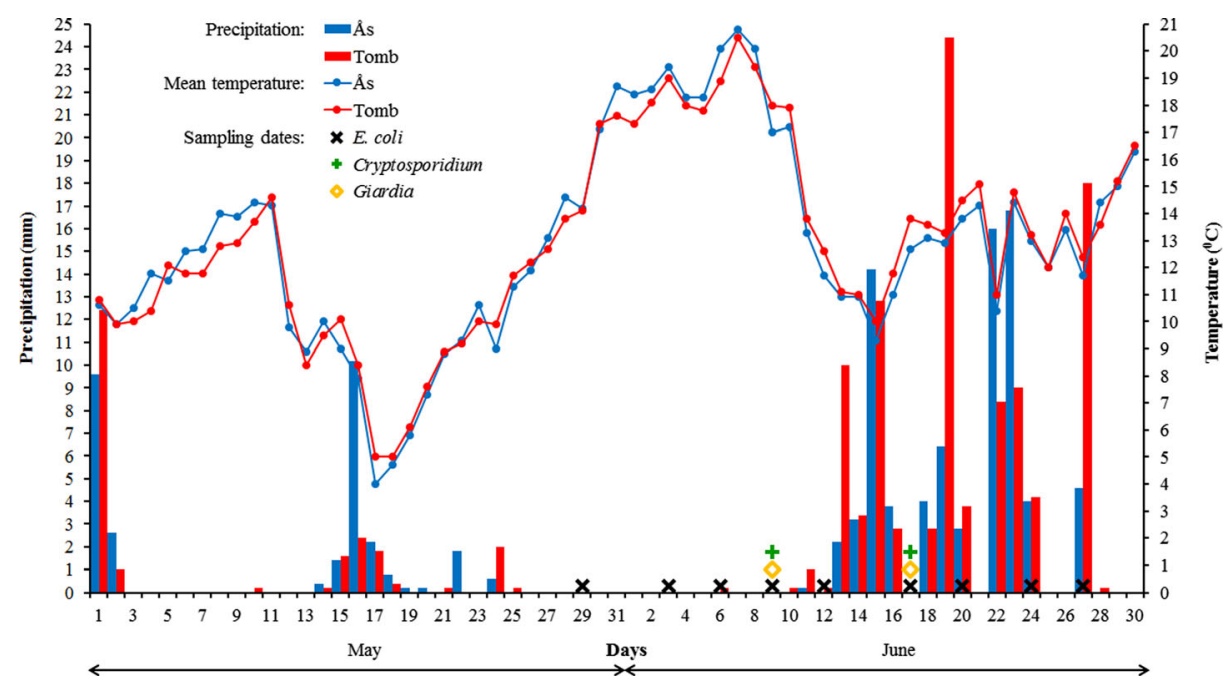

Fig. 2 Precipitation and temperature records and the sampling schedule at the study sites 
water. All sampling sets (i.e. 27 water samples; three water samples collected nine times) were analysed for E. coli, but only two sampling sets were analysed for Cryptosporidium and Giardia due to the high analysis costs and the financial restrictions of the study.

\subsubsection{Tests of Water Pollution with E. coli}

Laboratory analyses of $E$. coli bacteria in all water samples collected were performed at Bioforsk, Soil and Environment Division in Ås. E. coli concentrations were examined using the Colilert 18/Quanti-Tray ${ }^{\circledR 2} 2000$ Method (IDEXX Laboratories Incorporated, Westbrook, Maine, USA). The scientific background of this method has been described elsewhere in greater detail (Paruch 2011).

Initial examination of the first set of water samples revealed that the tests for E. coli in the groundwater and the pond could be conducted on undiluted samples while the water samples taken from the stream required 10 -fold dilution prior to examination. The E. coli tests were performed in accordance with a four-step procedure, described as follows: 1) Sample/reagent mixture - the undiluted and/or diluted (with sterile distilled water as a standard procedure recommended by the Colilert method) samples at a total volume of $100 \mathrm{ml}$ were mixed with the Colilert 18 reagent in a $100 \mathrm{ml}$ autoclaved glass bottle (DURAN ${ }^{\circledR}$ ) and shaken until the regent was completely dissolved; 2) Tray sealing - the prepared mixtures were poured into the Quanti-Tray ${ }^{\circledR 2000 s}$ and sealed in an IDEXX Quanti-Tray Sealer; 3) Incubation - the sealed trays were incubated at $37{ }^{\circ} \mathrm{C}$ for $18 \mathrm{~h}$ (according to the manufacturer's and supplier's instructions); 4) E. coli detection - all wells on each tray with yellow colour and fluorescence (under UV light of $6 \mathrm{~W}$ and $365 \mathrm{~nm}$ ) were counted as positive for E. coli. After this procedure, the numbers of positive wells were generated by the Most Probable Number (MPN) technique using an MPN Generator Program Ver. 3.2 (IDEXX Laboratories Incorporated, Westbrook, Maine, USA). The final results were reported in terms of $E$. coli concentration in $100 \mathrm{ml}$ of the tested water and expressed as MPN/100 ml with a detection limit of $<1$ MPN/100 ml.

\subsubsection{Tests of Water Pollution with Cryptosporidium and Giardia}

Analyses of pathogenic intestinal protozoa were conducted by the Parasitology Laboratory at the Norwegian School of Veterinary Science in Oslo. The analytical procedure applied for detection of Cryptosporidium oocysts and Giardia cysts in the water samples has been described elsewhere in greater detail (Robertson and Gjerde 2001a). In brief, the analyses were conducted as follows: 1) Membrane filtration of sample (total volume of each tested/ filtered sample was 10 1); 2) Elution of material from the membrane filter; 3) Concentration of the eluted material by centrifugation; 4) Isolation of parasites from the concentrated eluted material by immunomagnetic separation; 5) Staining of the sample concentrate with monoclonal antibodies against Cryptosporidium oocysts and Giardia cysts labelled with a fluorescent label (AquaGlo, Waterborne Inc., New Orleans, USA) and DAPI, followed by examination by fluorescence microscopy, with differential interference contrast optics used for confirmation of identity.

\section{Results and Discussion}

At the study sites, May 2008 was the driest month of the entire 2008 growing season (data not shown), and was the driest May of the century to date. During this relatively dry period, 
isolated rainfall events occurred on the first 2 days of May in Ås and Tomb and then irregularly within 10 days during the second half of the month (Fig. 2).

While the total month sum of precipitation in Ås was $30 \mathrm{~mm}$, in Tomb only $22.4 \mathrm{~mm}$ of precipitation was recorded. The maximum total daily rainfall was $12.4 \mathrm{~mm}$, and occurred in Tomb (Fig. 2). The dry and warm period (with air temperatures reaching 20.8 and $20.5^{\circ} \mathrm{C}$ in Ås and Tomb, respectively) lasted over 2 weeks. In June 2008, a 2-week period of quite intensive rainfall associated with lower air temperatures occurred (Fig. 2).

The dry period during the growing season resulted in a high demand for irrigation, and all crops, in particular strawberries, were intensively irrigated. The weather conditions affected not only the quantity, but also the microbiological quality, of the water used. Although neither FIB nor intestinal protozoa were detected in water samples collected from the ground well, faecal contamination was detected in all surface water samples. This is unsurprising as it is widely accepted that surface water bodies are more vulnerable to contamination than groundwater reservoirs due to the lack of natural soil protection (Kistemann et al. 2002; Tryland et al. 2011).

The concentrations of $E$. coli in surface waters decreased continuously during the dry/warm period but increased immediately following the rainfall events (Figs. 3 and 4). This phenomenon has been previously reported (Kistemann et al. 2002; Whitman et al. 2008; Rijal et al. 2009; Tryland et al. 2011). Kleinheinz et al. (2009) found that an increase in bacterial concentrations in water is associated with almost all storms with rainfall greater than $6 \mathrm{~mm}$. In addition, the first precipitation event following the dry season may cause transport of FIB into water bodies, and the number of bacteria is influenced by precipitation events up to 1 week prior to sampling, although recent rainfall (up to 3 days) tends to exhibit the strongest relationship with bacteria numbers (Patz et al. 2008; Tryland et al. 2011). These findings associate well with the results obtained in this study, as the numbers of E. coli began to increase immediately after the rainfall following the dry/warm period and an increase was observed after precipitation greater than $6 \mathrm{~mm}$ (Figs. 3 and 4). Thereafter, the E. coli concentrations in both the stream and the pond rose continuously with the rainfall events.

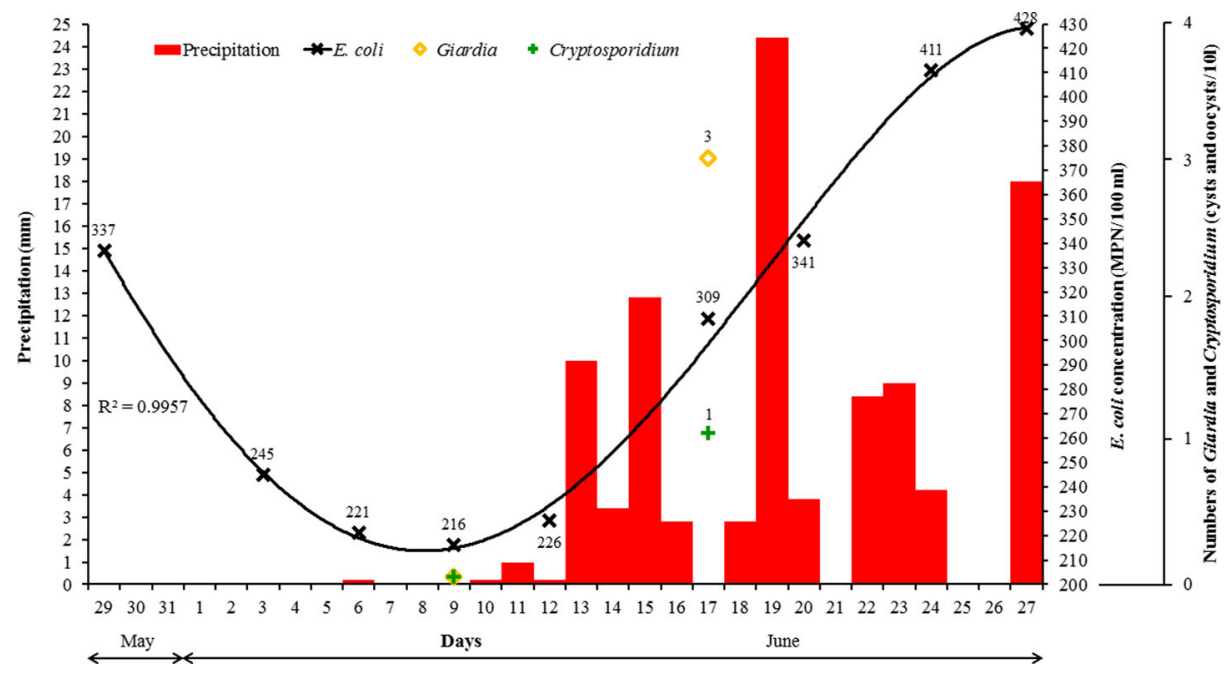

Fig. 3 Changes in microbial concentrations in the water samples collected from the stream Heiabekken throughout the weather fluctuations; the dry/warm and wet/cool periods 


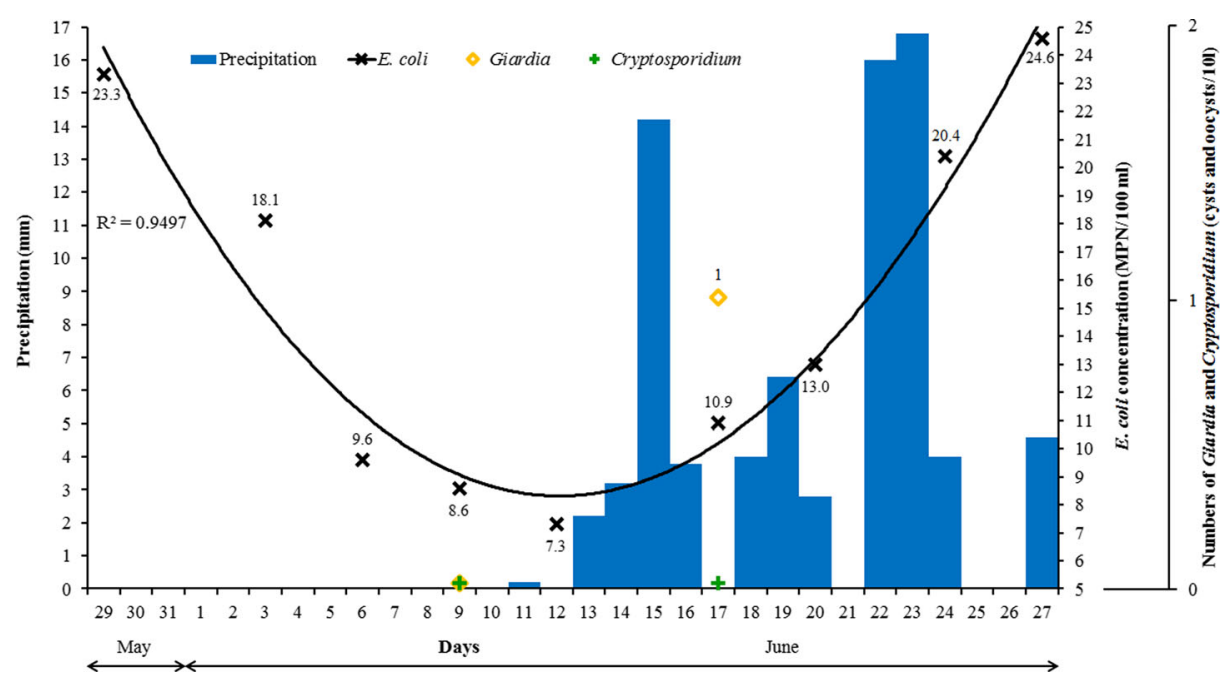

Fig. 4 Changes in microbial concentrations in the water samples collected from the pond on the strawberry plantation throughout the weather fluctuations; the dry/warm and wet/cool periods

The maximum concentrations of $E$. coli recorded in the stream and pond during the wet/cool period were approximately two and three times higher, respectively, than the minimum concentrations recorded in the dry/warm period, respectively (Figs. 3 and 4).

The results of this study cannot be directly compared with the hygienic parameters defined in the earlier Norwegian classification of water suitable for irrigation (SFT 1997), as these parameters refer to coliforms and thermotolerant coliform bacteria (TCB). These indicators can originate from the environment, and thus do not necessarily indicate faecal contamination (Paruch and Mæhlum 2012). However, an indirect comparison can be made as E. coli is a subgroup of TCB, and thus, from the theoretical point of view, concentrations of $E$. coli shall not exceed concentrations of TCB (Paruch and Mæhlum 2012).

According to the hygienic parameters used in the Norwegian classification, fruits and vegetables that are eaten raw without peeling should not be irrigated with water containing more than 2 TCB/100 ml (SFT 1997). This number was exceeded by minimal concentrations of $E$. coli in both irrigation water sources at the study sites (Figs. 3 and 4). In particular, the stream water was highly contaminated with $E$. coli, which exceeded more than 100 times the limit for TCB (Fig. 3). Alternatively, it is permitted that fruits and vegetables are irrigated with water containing up to $20 \mathrm{TCB} / 100 \mathrm{ml}$, but irrigation must be completed 2 weeks before harvesting (SFT 1997). Even with this alternative, the stream water contained $E$. coli concentrations more than 10 times higher than the limit for TCB, and therefore could not be classified as being suitable for irrigation water.

Although the presence of FIB indicates recent faecal contamination, the bacteria may also survive in soil sediments, sand and filter materials (Patz et al. 2008; Whitman et al. 2008; Paruch 2011), be re-suspended during precipitation events and flushed with subsequent runoff directly into water bodies. Therefore, diffuse pollution from agricultural runoff may also be considered to represent faecal contamination of surface waters. As reported by Sargeant et al. (2004), animals such as cattle contribute not only to direct faecal water pollution (droppings of excreta), but also to indirect contamination by facilitating the transmission of $E$. coli, as cattle movements raise bacteria surviving in the soil to the surface enabling their runoff. Although 
rainfall is the main vehicle transporting FIB into water bodies, it has also been reported that E. coli can remain viable in aerosols, and thus wind can also disperse bacteria, causing contamination of surface waters (Sargeant et al. 2004).

Similarly, Cryptosporidium oocysts and Giardia cysts can be re-suspended from soil and sediments (where they may survive for months) and transported for long distances after rainfall events (Kistemann et al. 2002; Tryland et al. 2011). These parasitic protozoa were not detected in water samples collected at the study sites during the dry/warm period, but the analyses of samples collected after rainfall revealed contamination with both Cryptosporidium oocysts and Giardia cysts (Figs. 3 and 4).

Faecal contamination was assumed to be of animal origin, and for the stream study site (Heiabekken), the contribution of the poultry farm (located upstream) was assumed to be important. The lowest and highest concentrations of E. coli in this stream (Fig. 3) were 30- and 17-times higher, respectively, than the corresponding concentrations in the standing surface water (the pond near Ås) (Fig. 4). Furthermore, the parasitic protozoa predominated in Heiabekken, where three Giardia cysts (the number might have been even higher as many cyst like objects were detected, which could have been deformed/partially decayed Giardia cysts) and one Cryptosporidium oocyst were detected in comparison to one cyst and no oocysts detected in the pond (Figs. 3 and 4). Although both parasites are most commonly associated with animals such as cattle and sheep, some species of Cryptosporidium can occur in chickens (Soltane et al. 2007; Government of Canada 2009; Nakamura et al. 2009) and may also be transported to the water source via wild aquatic birds. Gulls, geese and ducks, which lead both terrestrial and aquatic lifestyles, transmit these parasites over great distances and different locations (Ziegler et al. 2007; Tsiodras et al. 2008; Majewska et al. 2009; Plutzer and Tomor 2009; Lasek-Nesselquist et al. 2010). Such birds, in particular gulls, had been observed at the study sites on every occasion of sampling. Bird droppings were commonly found around the sites, thus they can also be expected in surface waters. Alternative sources of contamination potentially containing these parasites could not be identified.

The FIB characterized by $E$. coli was examined using the Colilert system which does not require any confirmation steps and demonstrates the highest accuracy in the detection of $E$. coli in comparison to other standard methods used (Paruch 2011). Regarding the examination of parasitic protozoa, the analytical method results in considerable losses, such that the actual contamination of the water was probably higher than that described in these results. Therefore, a scientifically valid assessment of microbial risk associated with irrigation water could not have been performed. In future studies, we would recommend that molecular methods are also employed, not only as an alternative detection method, but also to determine the species and subtype of parasites detected and thus determine not only their public health significance (not all species of Cryptosporidium and Giardia are infectious to humans), but also where they have probably originated.

\section{Conclusions}

This preliminary research study revealed that extreme weather alternations influenced the microbial quality of water used for agricultural irrigation in Southeast Norway. The quality was expressed in terms of concentrations of E. coli, Cryptosporidium oocysts and Giardia cysts. Although these microbes were not detected in groundwater (naturally protected by soil mass), they were present in surface water samples collected from a stream and a pond. The presumed origin of these microbes in the surface waters was animal faecal contamination; samples of stream water revealed $E$. coli concentrations up to 30 times higher than in water 
samples collected from the pond, and this may be related to the poultry farm located upstream of the sampling site.

During the dry/warm period, concentrations of E. coli were lower and contamination with Cryptosporidium oocysts and Giardia cysts was not detected in the surface waters tested. Nevertheless, even during this period, the quality of these waters was still not acceptable for irrigation of fruits and vegetables, which are eaten raw without peeling according to the Norwegian classification of water suitable for irrigation. E. coli concentrations increased directly after the first rainfall events and the longer the wet/cool period, the higher were the concentrations of $E$. coli detected. Rainfall for almost 2-weeks increased E. coli numbers by 100 and $200 \%$ in the stream and the pond, respectively. During this wet/cool period, Cryptosporidium oocysts and Giardia cysts were also detected in the water samples.

These extreme variations in E. coli concentrations and the detection of Cryptosporidium oocysts and Giardia cysts demonstrates that surface water sources are vulnerable to weather variations in Southeast Norway. As the groundwater tested was not affected by the weather variations and was of good microbial quality throughout the study period, this could be suggested as a source for irrigation water for vegetables and fruits in these locations.

Climate change appears to be inevitable and more extreme precipitation is predicated and thus greater abrupt runoff will occur; thus, our data suggest that greater emphasis must be placed on the quality of irrigation water, and local/national guidelines need to be developed. Further studies that expand upon this preliminary research are required to address the impact of frequent weather fluctuations, along with the larger picture of climate change, on the microbial safety of irrigation water and thus on human and environmental health.

\section{References}

Baldursson S, Karanis P (2011) Waterborne transmission of protozoan parasites: review of worldwide outbreaks an update 2004-2010. Water Res 45:6603-6614

Carr RM, Blumenthal UJ, Duncan Mara D (2004) Guidelines for the safe use of wastewater in agriculture: revisiting WHO guidelines. Water Sci Technol 50:31-38

Edberg SC, Rice EW, Karlin RJ, Allen MJ (2000) Escherichia coli: the best biological drinking water indicator for public health protection. J Appl Microbiol 88:106-116

European Commission (2007) Communication from the Commission to the European Parliament and the Council - Addressing the challenge of water scarcity and droughts in the European Union. COM (2007) 414 final, Brussels

European Environment Agency (2009) Water resources across Europe - confronting water scarcity and drought. EEA Report No 2, Copenhagen

Gaut S, Robertson L, Gjerde B, Dagestad A, Brattli B (2008) Occurrence of Cryptosporidium oocysts and Giardia cysts in Norwegian groundwater wells in bedrock. J Water Health 6:383-388

Government of Canada (2009) Canadian national integrated enteric pathogen surveillance system (C-EnterNet) 2007. Annual report. Public Health Agency of Canada, Guelph

Haller L, Pote J, Loizeau J-L, Wildi W (2009) Distribution and survival of faecal indicator bacteria in the sediments of the Bay of Vidy, Lake Geneva, Switzerland. Ecol Indic 9:540-547

Karanis P, Kourenti C, Smith H (2007) Waterborne transmission of protozoan parasites: a worldwide review of outbreaks and lessons learnt. J Water Health 5:1-38

Kistemann T, Claßen T, Koch C, Dangendorf F, Fischeder R, Gebel J, Vacata V, Exner M (2002) Microbial load of drinking water reservoir tributaries during extreme rainfall and runoff. Appl Environ Microbiol 68:21882197

Kleinheinz GT, McDermott CM, Hughes S, Brown A (2009) Effects of rainfall on E. coli concentrations at door county, wisconsin beaches. Int. J Microbiol 2009:1-9

Lasek-Nesselquist E, Welch DM, Sogin ML (2010) The identification of a new Giardia duodenalis assemblage in marine vertebrates and a preliminary analysis of $G$. duodenalis population biology in marine systems. Int J Parasitol 40:1063-1074 
Lee CM, Lin TY, Lin C-C, Kohbodi GA, Bhatt A, Lee R, Jay JA (2006) Persistence of fecal indicator bacteria in Santa Monica Bay beach sediments. Water Res 40:2593-2602

Majewska AC, Graczyk TK, Słodkowicz-Kowalska A, Tamang L, Jedrzejewski S, Zduniak P, Solarczyk P, Nowosad A, Nowosad P (2009) The role of free-ranging, captive, and domestic birds of Western Poland in environmental contamination with Cryptosporidium parvum oocysts and Giardia lamblia cysts. Parasitol Res 104:1093-1099

Nakamura AA, Simões DC, Antunes RG, da Silva DC, Meireles MV (2009) Molecular characterization of Cryptosporidium spp. from fecal samples of birds kept in captivity in Brazil. Vet Parasitol 166:47-51

Palese AM, Pasquale V, Celano G, Figliuolo G, Masi S, Xiloyannis C (2009) Irrigation of olive groves in Southern Italy with treated municipal wastewater: Effects on microbiological quality of soil and fruits. Agr Ecosyst Environ 129:43-51

Paruch AM (2011) Long-term survival of Escherichia coli in lightweight aggregate filter media of constructed wastewater treatment wetlands. Water Sci Technol 63:558-564

Paruch AM, Mæhlum T (2012) Specific features of Escherichia coli that distinguish it from coliform and thermotolerant coliform bacteria and define it as the most accurate indicator of faecal contamination in the environment. Ecol Indic 23:140-142

Patz JA, Vavrus SJ, Uejio CK, McLellan SL (2008) Climate change and waterborne disease risk in the great lakes region of the U.S. Am J Prev Med 35:451-458

Plutzer J, Tomor B (2009) The role of aquatic birds in the environmental dissemination of human pathogenic Giardia duodenalis cysts and Cryptosporidium oocysts in Hungary. Parasitol Int 58:227-231

Rijal G, Petropoulou C, Tolson JK, DeFlaun M, Gerba C, Gore R, Glymph T, Granato T, O’Connor C, Kollias L, Lanyon R (2009) Dry and wet weather microbial characterization of the Chicago area waterway system. Water Sci Technol 60:1847-1855

Robertson LJ, Chalmers RM (2013) Foodborne cryptosporidiosis: is there really more in Nordic countries? Trends Parasitol 29:3-9

Robertson LJ, Gjerde B (2001a) Occurrence of Cryptosporidium oocysts and Giardia cysts in raw waters in Norway. Scand J Public Health 29:200-207

Robertson LJ, Gjerde B (2001b) Occurrence of parasites on fruits and vegetables in Norway. J Food Protect 64: 1793-1798

Robertson LJ, Hermansen L, Gjerde BK, Strand E, Alvsvåg JO, Langeland N (2006) Application of genotyping during an extensive outbreak of waterborne giardiasis in Bergen, Norway, during autumn and winter 2004. Appl Environ Microbiol 72:2212-2217

Robertson LJ, Gjerde B, Hansen EF, Stachurska-Hagen T (2009) A water contamination incident in Oslo, Norway during October 2007; a basis for discussion of boil-water notices and the potential for post-treatment contamination of drinking water supplies. J Water Health 7:55-66

Sargeant JM, Sanderson MW, Smith RA, Griffin DD (2004) Associations between management, climate, and Escherichia coli $\mathrm{O} 157$ in the faeces of feedlot cattle in the Midwestern USA. Prev Vet Med 66:175-206

SFT (1997) Klassifisering av miljøkvalitet i ferskvann. Veiledning 97:04. Statens forurensingstilsyn, Oslo (in Norwegian)

Soltane R, Guyot K, Dei-Cas E, Ayadi A (2007) Prevalence of Cryptosporidium spp. (Eucoccidiorida: Cryptosporiidae) in seven species of farm animals in Tunisia. Parasite 14:335-338

Tryland I, Robertson L, Blankenberg A-GB, Lindholm M, Rohrlack T, Liltved H (2011) Impact of rainfall on microbial contamination of surface water. Int J Clim Chang Strateg Manag 3:361-373

Tsiodras S, Kelesidis T, Kelesidis I, Bauchinger U, Falagas ME (2008) Human infections associated with wild birds. J Infection 56:83-98

Whitman RL, Przybyla-Kelly K, Shively DA, Nevers MB, Byappanahalli MN (2008) Sunlight, season, snowmelt, storm, and source affect $E$. coli populations in an artificially ponded stream. Sci Total Environ 390:448-455

Ziegler PE, Wade SE, Schaaf SL, Stern DA, Nadareski CA, Mohammed HO (2007) Prevalence of Cryptosporidium species in wildlife populations within a watershed landscape in southeastern New York State. Vet Parasitol 147:176-184 